\title{
Growth of micro and small scale enterprises and its driving factors: empirical evidence from entrepreneurs in emerging region of Ethiopia
}

\author{
Hayelom Abrha Meressa
}

Correspondence: hayelommeresa@ gmail.com

Accounting and Finance Department, Assosa University, Assosa, Ethiopia

\begin{abstract}
Purpose: The purpose of this study was to examine micro and small scale enterprises' growth determinants operating in Benishangul-Gumuz Regional State of Ethiopia as emerging region.

Design/methodology/approach: The study adopted an explanatory research design with arrangement of primary data collection via a cross-sectional survey questionnaire followed by mixed research approach. The sample of this study was 220 enterprises determined by Yamane's formula and selected using proportional stratified random sampling technique.
\end{abstract}

Findings: The result of regression analysis revealed that initial investment, access to land, access to finance, location, sectoral engagement, market linkage, and business experience are significant in explaining growth in one hand. On the other side, however, gender, education, ownership, formal recording, and financial management practice are found to be insignificant variables in determining enterprises' growth.

Research limitations/implications: More evidence is needed on micro and small scale enterprises' growth determinants before any generalization of the results can be made. In addition, the empirical tests were conducted only on 220 entrepreneurs since 2018. Therefore, the results of the study cannot be assumed to extend beyond this group of entrepreneurs to different study periods.

Practical implications: The study might help the entrepreneurs in addressing the factors affecting growth to take actions toward developing their performance and in turn contribute to employment, export participation, poverty alleviation, and women empowerment.

Originality/value: This paper adds to the literature on the determinants of microand small-scale enterprises' growth. In particular, it tests the impact of initial investment, access to land, access to finance, location, sectoral engagement, market linkage, business experience, education, ownership structure, and financial management practice on growth of enterprises.

Keywords: Assosa Zone, Constraints, Growth, Micro and Small Enterprises

(c) The Author(s). 2020 Open Access This article is licensed under a Creative Commons Attribution 4.0 International License, which permits use, sharing, adaptation, distribution and reproduction in any medium or format, as long as you give appropriate credit to the original author(s) and the source, provide a link to the Creative Commons licence, and indicate if changes were made. The images or other third party material in this article are included in the article's Creative Commons licence, unless indicated otherwise in a credit line to the material. If material is not included in the article's Creative Commons licence and your intended use is not permitted by statutory regulation or exceeds the permitted use, you will need to obtain permission directly from the copyright holder. To view a copy of this licence, visit http://creativecommons.org/licenses/by/4.0/. 


\section{Introduction}

To date, extensive evidence shows that growth of micro and small scale enterprises (MSSEs, hereafter) is a critical ingredient in sustainable development of developing economies (Mbugua et al. 2013). In Ethiopia, the importance of this sector is noticed on different documents like industrial policy, MSSE development strategy, and the growth and transformation plans I and II to accelerate growth and reduce poverty (Esubalew and Raghurama 2017). However, both the level of unemployment and quality of jobs remain a concern although growth and transformation through the promotion of the sector have been robustly underscored in various development plans of the country (Tarfasa et al. 2016). Moreover, operation and growth of these enterprises have been persistently challenged by numerous factors; even a significant number of enterprises in different parts of the country have collapsed and goes out of operation (Seyoum et al. 2016; Fissiha 2016).

So as to curb challenges of unemployment and identify growth determinants, a detailed and regular study at country, regional, and firm level is important to provide result-oriented and sustainable support to the sector (Woldeyohanes 2014; Abay et al. 2014 ; Fissiha 2016). For this reason, quite a number of studies have been carried out in different parts of the country to identify growth determinants. This includes the studies made by Tefera et al. 2013; Abay et al. 2014; Adem et al. 2014; Feleke 2015; Debelo et al. 2015; Aynadis and Mohammednur 2014; Leza et al. 2016; Tarfasa et al. 2016; Alemayehu and Gecho 2016; Fissiha 2016; and Seyoum et al. 2016 to mention a few. However, most of the studies provide neither consistent findings nor address MSSEs' growth determinants in the emerging regions of the country like Afar, Gambela, Somalia, and Benishangul-Gumuz Regional State. To the best of the researcher's knowledge, too limited studies were conducted in Benishangul-Gumuz. The first one is a study made by Abebe et al. (2016) that assessed the challenges and performances of MSSEs in a descriptive way neglecting inferential statistics. Secondly, a research was made by Abara and Banti (2017) which analyzed the role of financial institutions on growth of only 57 sampled enterprises using percentage change in assets as proxy of growth. Besides, this study incorporated only access to credit, firm size, and firm age to investigate growth influencing factors, ignoring more of growth constraint variables discussed in the literature.

In the same vein, apart from the Ethiopian context, empirical studies have been carried out in different parts of the world to identify the factors that affect MSSEs' growth. However, evidences in developed and developing countries revealed inconclusive findings with regard to the determinants. Although the impact and magnitude of variables on firm growth vary from country to country, region to region, and firm to firm, there are many common factors considered as growth determinants in literature of small business. To mention a few, initial investment, firm location, sectoral engagement, access to land, business experience, gender of owner, motivation of owner, education, market linkage, proper record keeping, financial management practice, and access to finance are among others. These variables were collected from studies made by Zhou and de Wit 2009; Loewe et al. 2013; Tefera et al. 2013; Abay et al. 2014; Adem et al. 2014; Feleke 2015; Debelo et al. 2015; Aynadis and Mohammednur 2014; Nganda et al. 2014; Leza et al. 2016; Tarfasa et al. 2016; Alemayehu and Gecho 2016; Fissiha 2016; and Seyoum et al. 2016 through systematic review. Consequently, the above backdrop suggests at least three reasons why additional research in the area of MSSEs is needed 
in the context of Ethiopia in general and Benishangul-Gumuz in particular as a developing region.

First, growth of MSSEs has been persistently challenged by numerous factors; even a significant number of enterprises in different parts of the country have collapsed and goes out of operation. Undoubtedly, small businesses in Benishangul-Gumuz are no exception to this. Second, despite the fact that past empirical studies of different countries have identified the common factors associated with small business growth, the influence and magnitude of each factor vary from one arena to the other which provide inconsistent findings that cannot be generalized and needs further research. Third, in the context of Ethiopia, existing studies on growth determinants mainly focus on the developed regions and less evidence is documented in emerging regions of the country in addition to mixed results that leave research gap.

Therefore, against this background, the purpose of this study was to examine the growth of micro and small scale enterprises and its driving factors operating in Assosa Zone, Benishangul-Gumuz Regional State of Ethiopia. The novelty of this paper is that it incorporated demographics, firm specifics, and external factors so as to fill the gap in the scant MSSEs' growth literature as an emerging region unlike the existing studies made by Abebe et al. (2016) and Abara and Banti (2017). Most importantly, the paper tried to answer the question of what factors influence growth of micro and small scale enterprises in Benishangul-Gumuz Region using regression analysis. The remainder of this paper is structured as follows: Section 2 discusses about review of related literature. Section 3 is about research methodology followed by Section 4 that presents empirical results and discussion. Finally, Section 5 provides the conclusion and thereafter forwards the recommendation.

\section{Literature review}

In the existing literature of micro and small business, many empirical studies have been conducted on enterprises' growth determinants, covering various scopes using different sample firms and methods globally. However, findings of many studies with regard to the variables influencing growth of firms produced numerous factors with different impact on growth. To identify the most commonly used variables as growth determinants, a concentrated and careful systematic review of literature was carried out on relatively recent empirical studies. Accordingly, the author reviewed studies conducted by Victoria et al. 2011; Tefera et al. 2013; Emmanuel et al. 2013; Assefa et al. 2014; Abay et al. 2014; Nganda et al. 2014; Aynadis and Mohammednur 2014; Debelo et al. 2015; Nathan et al. 2015; Wolde and Geta 2015; Nathan et al. 2015; Fissiha 2016; Alemayehu and Gecho 2016; Tarfasa et al. 2016; Leza et al. 2016; Kahando et al. 2017 randomly. Thereafter, fourteen frequently used variables namely initial investment, enterprises' location, access to land, business experience, gender of owner, enterprises' sectoral engagement, motivation, education, market linkage, technology adoption, access to finance, record keeping, ownership structure, and financial management practice were collected from the studies. The detail review on the nexus between each variable and firm growth is, therefore, discussed below to develop a clear conceptual framework.

\section{Location}

It is believed that firms located in urban areas tend to grow faster as compared to those located in rural areas because urban firms have access to a large market of consumers 
with high purchasing power compared to firms operating in rural areas (Tefera et al. 2013; Nathan et al. 2015). Moreover, enterprises located in urban areas have access to public infrastructures that comprise water, electricity, serviceable roads, telecommunication, electronic media, and postal services which are all crucial for business start-up, development, and growth irrespective of its size (Ahmad et al. 2012; Loewe et al. 2013; Abay et al. 2014; Wolde and Geta 2015). In other words, it means that firms that operate in an environment with poor infrastructure which constitutes the inability to access market, communication, power, and water and barrier to entry and hinder competitiveness grow slowly than their counterparts with better infrastructure (Oppong et al. 2014; Debelo et al. 2015).

\section{Business experience}

An enterprise's age has a significant effect on growth for the reason that older firms have more experience and a superior financial position to execute their business activities than their counterparts relatively (Afande 2015; Leza et al. 2016). Moreover, older firms are more likely to grow faster than younger firms because of the social capital they have gathered over time through experience (Nathan et al. 2015). Therefore, business experience and firm growth have a positive relationship, that is, as the age of an individual firm increases, the firm growth also increases (Fissiha 2016).

\section{Initial capital}

It is noted that enterprises that started their operation with a higher initial investment are more likely to grow than their counterparts which started operation with a relatively smaller initial investment (Tefera et al. 2013). In line with this, a study made by Fissiha (2016) on the determinants of MSSEs' growth in Ethiopia, the case of Bahirdar City found positive relationship between initial investment and growth.

\section{Sector}

In Ethiopia, it is believed that manufacturing and construction sectors grow faster compared with other sectors for the fact that the country's industrial development concern is on manufacturing sector (Tarfasa et al. 2016). In addition, manufacturing especially metal and wood working and construction tend to be more successful than other sectors in the Ethiopian context. This might be related to skill and experience of the sectors (Assefa et al. 2014).

\section{Access to land}

Evidently, business operating in premises allotted by government agencies had better chance of survival compared to those set up in privately rented premises (Leza et al. 2016).

\section{Gender}

Male-owned and/or managed firms have better growth than female-owned and/or managed firms (Nganda et al. 2014). A number of justifications have been argued as to why female-owned firms grow slowly than male-owned firms. This may be due to the fact that women owners of firms in some countries have greater problems regarding 
innumeracy, illiteracy, and lack of business skills. Besides, women are more risk-averse and belong to less growth-oriented networks (Loewe et al. 2013). In addition, it could be because of women's concentration in small growing sectors, for example, trading and service (Gebreeyesus 2007).

\section{Motivation}

Motivated entrepreneurs always demonstrate high level of creativity and innovation and show high level of management skills and business know-how. Indeed, they are transformational in nature and use failure as a tool and springboard for success (Nyang'au 2014). Therefore, growth prospects of firm owners with lower or negative type of motivation, such as unemployment is lower (Alemayehu and Gecho 2016).

\section{Education}

Education is presumably related to knowledge and skills, motivation, self-confidence, problem solving ability, commitment, and discipline. Higher education is expected to increase the ability to cope with problems and seize opportunities (Papadaki and Chami 2002). The role of education on growth is explained through its effect on exposure to new information and processing that could have positive impact on production and distribution of goods and services (Leza et al. 2016). In addition, it is believed that operators with higher educational qualification are expected to make better quality decisions to manage a firm in a way that reduces the likelihood of failure (Victoria et al. 2011). Therefore, firms owned and managed by entrepreneurs with higher formal education experience higher growth than their counterparts (Yeboah 2015).

\section{Market linkage}

Firms can have forward linkage with customers or other resellers and backward linkage with their raw material suppliers to get the needed materials to produce goods or services (Debelo et al. 2015). The absence or low supply of raw materials may increase the cost of production and bring other drawbacks like stagnation, low quality of products, and poor performance among others (Emmanuel et al. 2013). This is to mean that adequate supplies of raw materials ensure good growth of firms and unavailability of raw materials can be barrier for growth. Therefore, market linkage and enterprises' growth have positive relationship (Amentie et al. 2016).

\section{Record keeping}

Accounting statements are used as to bring information to managers, business owners, and external users of the financial aspect of business entities to make decision (Mutua 2015). Therefore, availability of accounting information is important for business planning, organization, and control function of firms (Abdul-Rahamon and Adejare 2014). In addition, relevant accounting information could help the stakeholder of firms to make wise decisions to reduce uncertainty in decision-making. Therefore, a regular and organized record keeping practice enables enterprises to calculate profitability by clearly determining sales and expenses and helps to mitigate faults associated to production, marketing, and purchasing decisions (Lakew and Birbirsa 2017). Moreover, record keeping is essential for an entrepreneur to know what is happening in their 
business, how much has been sold, what the costs are, what activities are profitable, whether selling prices leave a suitable margin against cost, and so on (Ntim et al. 2014). To conclude, record keeping is expected to have a positive effect on growth.

\section{Information and communication technology}

Information and communication technology (ICT) adoption captures the use of modern technological products/services like websites, on-line sales, and computerized production system (Nathan et al. 2015). Accordingly, it is believed that enterprises that use ICT grow faster than their counterparts because using ICT can improve and strengthen customer relationships, enhance firm image, enhance information exchange, and enable them to compete with other firms (Papadaki and Chami 2002; Anga 2014). Moreover, having a social network is a valuable asset that can help an entrepreneur to obtain access to information as well as resources like credit. Social networks can play higher role in helping entrepreneurs to overcome obstacles related to transaction costs, contract enforcement, and regulation (Wolde and Geta 2015).

\section{Financial management practice}

In business finance, firms are established to operate into the foreseeable future. Business enterprises are able to survive based on the business experience of their operators, not surprisingly; financial management practice is at the heart (Attom 2013). Although lack of financial resources is the biggest problem in MSSEs, good financial management practice is most important and unquestionable, because inefficiencies in financial management result in poor financial performance and eventually lead to firm failure (Jennifer and Dennis 2015). Firms may fail if they do not manage their business like business, irrespective of their size. It is believed that better financial information means better control and therefore improve chance of success. Thus, enterprises should adopt and use sound financial management practices so that failure of businesses can be prevented (Gawali and Gadekar 2017).

\section{Access to credit}

Availability of credit ensures smooth operation of firms as it injects working capital. Thus, the likelihood of failure of firms is low if there is access to finance (Victoria et al. 2011). MSSEs which have access to finance grow better than those which have shortage of capital (Leza et al. 2016). In other words, enterprises with limited debt financing growth potential is lower than those enterprises having access to debt financing (Abay et al. 2014).

\section{Ownership structure}

Ownership structure of firms affects their growth through the degree of risk-taking. The key argument is that sole proprietors are usually risk-averse and more often prefer investing in low-risk items attracting low rates of return comparing to partnership. On the other hand, however, partnership firms are risk-takers who can start even risky business that attract high rates of return and drive their growth (Nathan et al. 2015). This is to mean that the spirit of belongingness and the need to increase earning is very high when the number of owner increases relatively in many business firms 
(Alemayehu and Gecho 2016). In addition, benefits associated with the presence of partners may include better capital, functional expertise, and a broader range of management experience comparing with sole proprietor firms (Papadaki and Chami 2002). Therefore, MSSEs owned by partnership may have better growth compared with those privately owned enterprises (Tarfasa et al. 2016). Finally, the following conceptual framework (Fig. 1) was developed based on the above detail review to show the relationship between MSSEs' growth and its driving factors.

\section{Research methodology}

Paradigm and study design

The design of research is shaped by researchers' mental models or frames of references that they use to organize their reasoning and observations (Bhattacherjee 2012). Therefore, any design can be selected by researchers based on the nature of research problem and questions to address the problem (Creswell 2012). Accordingly, researchers could choose among different types of possible research designs depending on purpose of the research, method of data collection,time dimension, and research approach as an architect chooses among the possible building designs depending on the purpose of the building, method of construction, time of construction, and other relevant factors (Gebru 2010). The current study, therefore, employed a mixed explanatory crosssectional survey research design with primary and secondary data.

\section{Data type and source}

The study used both primary and secondary data. The primary data were collected from selected micro and small enterprises in Assosa zone in 2018 G.C. Besides,

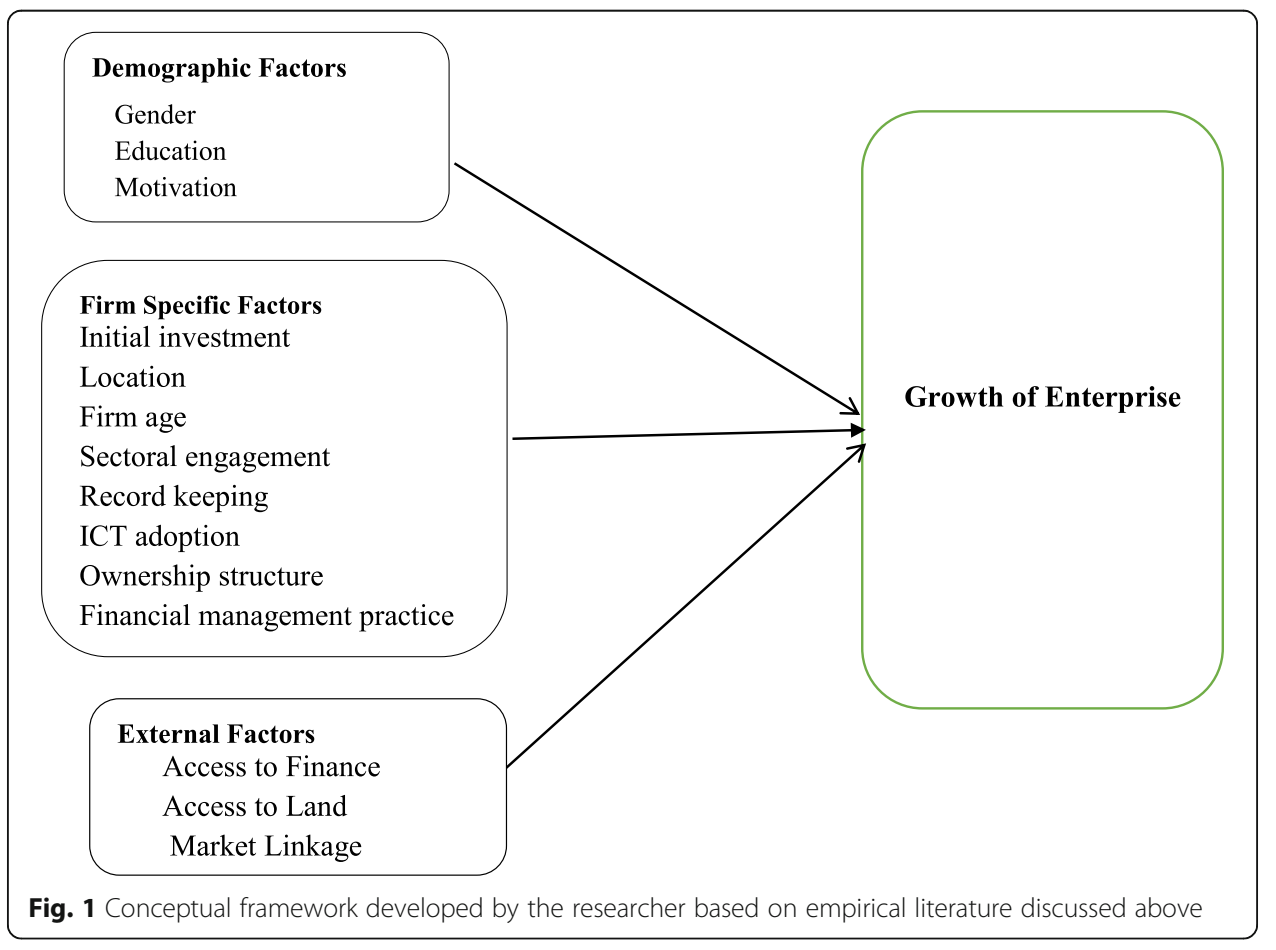


secondary data were collected from documents available in Assosa zone micro and small enterprises agency and records of enterprises under investigation.

\section{Data collection instruments}

The main data gathering instruments used in this study were both open- and closeended questionnaires to collect primary data and document review to collect secondary data, respectively.

\section{Construction of questionnaire}

The questionnaire was prepared in the English language from the available literature (Abay et al. 2014; Adem et al. 2014; Alemayehu and Gecho 2016; Leza et al. 2016 ; Tarfasa et al. 2016). Moreover, reliablity and validity of the instrument was also checked. Reliability is the degree to which the measure of a construct is consistent, and validity examines how well a given measurement scale is measuring the theoretical construct that it is expected to measure. Reliability can be checked using test-retest measurements of the same construct administered to the same sample at two different points in time. Besides, validity can be assessed based on correlational coefficient of pilot test data in quantitative research (Bhattacherjee 2012). Accordingly, prior to the commencement of the actual survey, the survey instrument was first reviewed by lecturers of accounting and finance department in Assosa University for validity and then pretested to evaluate its suitability on 30 piloted entrepreneurs from Assosa and Bambasi weredas. Thereafter, a test-retest method was used to examine the reliability of the instrument. To this end, the instrument was administered twice to the same group of subjects at an interval of 2 weeks and gave a correlation coefficient of 0.812 that indicates high reliability of the instrument for the fact that coefficient of 0.5 and above is deemed reliable (Kothari 2004).

\section{Population, sample size, and sampling technique}

There were a total of 491 enterprises operating in Assosa Zone according to the MSSEs' agency data during 2018 G.C. Accordingly, the target population of this study comprised all these enterprises. To this effect, an appropriate sample size was determined from these active enterprises using a simplified formula which is developed by Yamane (1967).

$$
\begin{aligned}
& \text { Sample size }=\left(\frac{\text { population size }}{1+\text { population size }\left(\text { level of precision }{ }^{2}\right)}\right) \\
& =\left(\frac{491}{1+491\left(0.05^{2}\right)}\right)=220.427=220
\end{aligned}
$$

where the level of precision $=5 \%$

Therefore, a representative sample of 220 enterprises was included in the study. As far as there is heterogeneity within the enterprises in terms of location and sector, stratification was carried out to create homogenous groups from the target population. 
The stratification technique was based on enterprises' location and sectoral operation. As a result, the enterprises were grouped into manufacturing sector, construction sector, service sector, agricultural sector, and trade to create operational homogeneity in each group. After stratification, proportional random sampling technique was applied to select sample elements from each stratum. The proportional sample of enterprises, considering their sectoral heterogeneity and heterogeneity in geographical location is depicted in Table 1.

\section{Variable measurement and model specification}

While specifying an empirical model, identification of dependent and independent variables with their measurement is a matter of no choice. Cognizant of this, the dependent variable of the current study is growth of MSSEs. Besides, initial investment, location of MSSEs, enterprise's sector, access to land, MSSEs' age, gender of owner, motivation of owner, owner's education, enterprise's linkage, ICT adoption, and access to finance were the independent variables included in the empirical model.

Empirical studies provide different proxies for growth of micro and small enterprise. Among these, total asset, sales, employment size, profit, and capital are mostly known (Tefera et al. 2013). These measures depend upon the ease of availability of the data and good judgment of the researcher. In view of this, employment growth is mostly used in MSSEs' growth literature in Ethiopia since MSSEs are looked from employment creation perspective and data on employment size is easily available (Gebreeyesus 2007; Tefera et al. 2013; Abay et al. 2014; Tarfasa et al. 2016; Fissiha 2016; Leza et al. 2016). However, the safe way of measuring growth is to have comprehensive measures than relying on a single indicator (Alemayehu and Gecho 2016). Accordingly, employment and capital growth rates were considered as best fitted measures of enterprises' growth to align with industrial development strategic plan of the country and MSSEs' definition criteria. The list of variables and their measurement is depicted in Table 2.

In most growth-related studies, both multiple linear regression model and binary logistic regression model could be applicable. In Ethiopia, for instance, Alemayehu and Gecho (2016); Abay et al. (2014); Feleke (2015) and Tefera et al. (2013) used binary logistic regression model in their studies. However, Adem et al. (2014); Leza et al. (2016); Tarfasa et al. (2016); and Fissiha (2016) used multiple regression in their studies. Therefore, both logistic and multiple regressions could be used in growth-related studies. On

Table 1 Summary of selected enterprises based on proportional random sampling

\begin{tabular}{|c|c|c|c|c|c|c|c|c|c|c|c|c|c|c|c|c|}
\hline \multirow[t]{3}{*}{ Sector } & \multicolumn{16}{|c|}{ Wereda } \\
\hline & \multicolumn{2}{|c|}{ Assosa } & \multicolumn{2}{|c|}{ Bambasi } & \multicolumn{2}{|c|}{ Homosha } & \multicolumn{2}{|c|}{ Menge } & \multicolumn{2}{|c|}{ Sherkole } & \multicolumn{2}{|c|}{ Kurmuk } & \multicolumn{2}{|c|}{ Oda } & \multicolumn{2}{|c|}{ Total } \\
\hline & $\mathrm{P}^{*}$ & $\mathrm{~S}^{*}$ & $\overline{P^{*}}$ & $\mathrm{~S}^{*}$ & $\mathrm{P}^{*}$ & $\mathrm{~S}^{*}$ & $\mathrm{P}^{*}$ & $\mathrm{~S}^{*}$ & $\mathrm{P}^{*}$ & $\mathrm{~S}^{*}$ & $\mathrm{P}^{*}$ & $S^{*}$ & $\mathrm{P}^{*}$ & $S^{*}$ & $\mathrm{P}^{*}$ & $S^{*}$ \\
\hline Manufacturing & 7 & 3 & 6 & 3 & 4 & 2 & 3 & 1 & 1 & 0 & 2 & 1 & 1 & 0 & 24 & 10 \\
\hline Construction & 35 & 16 & 8 & 3 & 11 & 5 & 29 & 13 & 13 & 6 & 4 & 2 & 6 & 3 & 106 & 48 \\
\hline Service & 25 & 11 & 23 & 10 & 6 & 3 & 8 & 4 & 7 & 3 & 7 & 3 & 13 & 6 & 89 & 40 \\
\hline Agriculture & 114 & 51 & 29 & 13 & 17 & 7 & 20 & 9 & 3 & 2 & 18 & 8 & 18 & 8 & 219 & 98 \\
\hline Trade & 9 & 4 & 15 & 7 & 2 & 1 & 6 & 3 & 7 & 3 & 11 & 5 & 3 & 1 & 53 & 24 \\
\hline Total & 190 & 85 & 81 & 36 & 40 & 18 & 66 & 30 & 31 & 14 & 42 & 19 & 41 & 18 & 491 & 220 \\
\hline
\end{tabular}

Ratio $=220.427 / 491=0.449$

$\mathrm{P}^{*}$ population, $\mathrm{S}^{*}$ sample 
the one side, multiple linear regression could be chosen if the growth measure, used as the dependent variable, takes a continuous measure. On the other hand, binary logistic regression model could be used if the growth measure, used as the dependent variable, takes a discrete measure. In the current study, the following general multiple linear regression model was specified consistent with that of Adem et al. (2014); Leza et al. (2016); Tarfasa et al. (2016); and Fissiha (2016) since enterprises' growth is considered as a continuous variable.

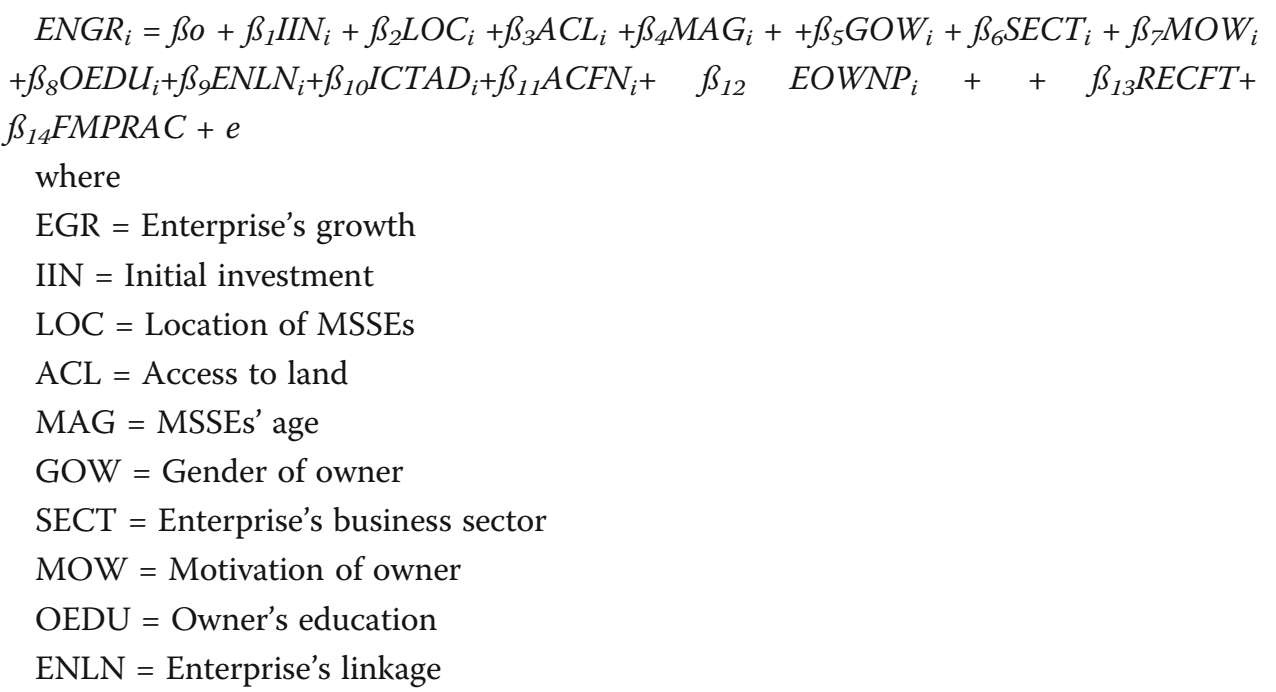

Table 2 Nature and measurement of variables

\begin{tabular}{|c|c|c|c|c|}
\hline No. & Variable & Notation & Nature & Measurement \\
\hline & $\begin{array}{ll}\text { Growth } & \text { Employment } \\
\text { rate } & \text { growth rate }\end{array}$ & EMPLGR & Continuous & $\begin{array}{l}\text { Change in employment size between the years of } \\
\text { beginning and sampling periods divided by age of the } \\
\text { enterprise }\end{array}$ \\
\hline & $\begin{array}{l}\text { Capital } \\
\text { growth rate }\end{array}$ & CAPGR & Continuous & $\begin{array}{l}\text { Change in capital between the years of beginning and } \\
\text { sampling periods divided by age of the enterprise }\end{array}$ \\
\hline 1 & Initial investment & $\| N$ & Continuous & Startup capital of the enterprise in birr \\
\hline 2 & Location of MSSEs & LOC & Categorical & $\begin{array}{l}(1=\text { Assosa, } 2=\text { Bambasi, } 3=\text { Oda, } 4=\text { Menge, } 5= \\
\text { Sherkole, } 6=\text { Homosha, and } 7=\text { Kurmuk })\end{array}$ \\
\hline 3 & Access to land & $\mathrm{ACL}$ & Dummy & 1 if they have access to land and 0 if otherwise \\
\hline 4 & MSSEs' age & MAG & Continuous & Previous work experience in years \\
\hline 5 & Gender of owner & GOW & Dummy & 1 if male-owned and 0 if otherwise \\
\hline 6 & Enterprise's sector & SECT & Categorical & $\begin{array}{l}(1=\text { agriculture, } 2=\text { trade, } 3=\text { construction, } 4=\text { service, } \\
\text { and } 5=\text { manufacturing })\end{array}$ \\
\hline 7 & Motivation of owner/s & MOW & Dummy & $\begin{array}{l}1 \text { if owners join MSSE by choice and } 0 \text { if it is by lack of } \\
\text { alternative }\end{array}$ \\
\hline 8 & Owner's education & OEDU & Categorical & $\begin{array}{l}(1=\text { informal/primary, } 2=\text { secondary, } 3=\text { TVET, and } 4= \\
\text { university })\end{array}$ \\
\hline 9 & Enterprise's linkage & ENLN & Dummy & $\begin{array}{l}1 \text { if they have access to market linkage and } 0 \text { if } \\
\text { otherwise }\end{array}$ \\
\hline 10 & ICT adoption & ICTAD & Dummy & 1 if they have ICT adoption and 0 if otherwise \\
\hline 11 & Access to finance & ACFN & Dummy & 1 if enterprises have access to finance and 0 if otherwise \\
\hline 12 & $\begin{array}{l}\text { Recording financial } \\
\text { transaction }\end{array}$ & RECFT & & $\begin{array}{l}1 \text { if there is record keeping of financial transactions and } \\
0 \text { if otherwise }\end{array}$ \\
\hline 13 & Enterprise's ownership & EOWNP & Dummy & 1 if enterprise owned by $\geq 2$ persons and 0 if otherwise \\
\hline 14 & $\begin{array}{l}\text { Financial management } \\
\text { practice }\end{array}$ & FMPRAC & & $\begin{array}{l}1 \text { if there is financial management practice and } 0 \text { if } \\
\text { otherwise }\end{array}$ \\
\hline
\end{tabular}




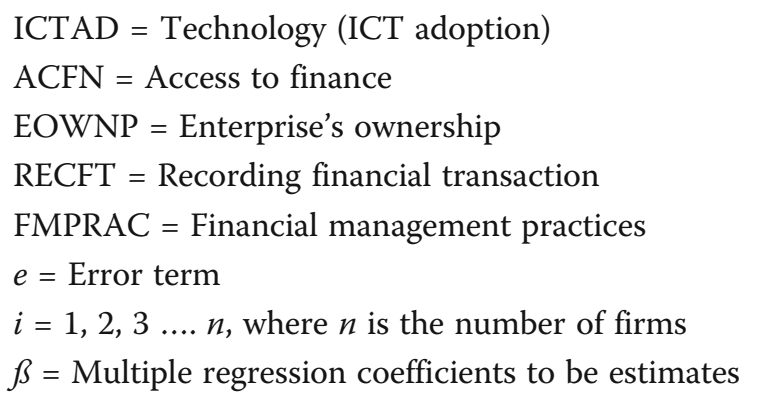

\section{Empirical results and discussion on the growth driving factors}

As means of data analysis, both descriptive and multiple regression analysis based on ordinary least square (OLS) estimation were applied. To do so, STATA software version 13 was used for statistical treatment. The data for this study were obtained from the micro and small scale enterprises survey, 2018. Preliminary results of the study were analyzed using simple percentages and present in the form of tables and figures. The study targeted 220 questionnaires; however, 206 questionnaires were successfully filled and returned (93.6\%) and the remaining questionnaires were with no full information for the purpose of analysis as shown in Table 3.

The result of the survey indicates that male-owned enterprises were $67.35 \%$, while only $32.55 \%$ were female-owned businesses enterprises. The participation of women is lower relative to men though the sector is expected to increase women empowerment. This may be due to the attitude of society and cultural norms that considered men as superior and leaving a role to women to bear more family responsibility at home rather than engaging themselves in business. This could, therefore, be a challenge to the sector in the study area.

With regard to motivation of enterprises' owners, almost $68.83 \%$ of the entrepreneurs joined the business by their choice which could be considered as prospect and the remaining $31.17 \%$ of the owners joined their business because of lack of alternative as of the 2018 survey. This could be considered as best prospect for the enterprises for the fact that motivated entrepreneur are ready to accept different risks and put mechanisms of risk management program either to prevent, mitigate, or cope with existed risks using mixed tools of proactive and financing alternatives.

Table 4 revealed that majority of the enterprises, i.e., almost $64.1 \%$ of the enterprises, finance their businesses internally from their own source. This implies that the proportion of enterprises that finance their business through borrowing from financial institutions is found to be not easy despite the fact that finance is indispensable for expansion of business for any sector. This signifies that the supply of credit to these enterprises is below their demand. In fact, it seems that access to finance appears to be a very severe or major obstacle as reported by the majority of micro and small enterprise owners.

Table 3 Response rate of questionnaire

\begin{tabular}{lll}
\hline Questionnaire & Frequency & Percentage \\
\hline Returned & 206 & $93.6 \%$ \\
Not returned & 14 & $6.4 \%$ \\
Total & 220 & $100 \%$ \\
\hline
\end{tabular}

Source: Author's computation based on firm survey (2018) 
Those entrepreneurs with access to formal finance even did not obtain the loan as per their request; rather, institutions provide credit below the request of entrepreneurs. Therefore, there are problems of accessing to credit and inadequacy even for the accepted requests which could be considered as challenge for the firms.

According to Fig. 2, 45\% of the sampled enterprises were engaged in the agricultural sector followed by the construction sector (22\%), while the remaining 18, 11 , and $4 \%$ were operating in the service, trade, and manufacturing sectors, respectively.

Figure 3 revealed that $40 \%$ of the sampled enterprises were operated in Assosa Wereda, $16 \%$ in Bambasi, followed by enterprises in Menge Wereda (14\%), while the remaining $24 \%$ shared equally ( $8 \%$ each) were operating in Oda, Homosha, and Kurmuk. The least 6\% were located in Sherkole Wereda.

Besides, almost $58.93 \%$ of micro and small scale enterprises have weak formal recording of economic transactions though the sector's development strategy recommends the enterprises to establish a financial record keeping system in the case of new enterprises or present audited financial reports in the case of existing enterprises. Therefore, this could be a challenge for the enterprises.

With regard to educational status of enterprises' owners, about $41.7 \%$ of the sample respondents were TVET graduates, $28.3 \%$ of the respondents completed secondary school, $23.6 \%$ of them were with education in elementary/informal, and $6.4 \%$ were university graduates as described in Fig. 4. Thus, higher percentage covers TVET which is a prospect to the enterprises. In addition, this supports micro and small scale enterprise development strategy as long as the directions provided in Ethiopia's industrial development strategy give mandate to TVET colleges in order to provide industrial extension services for the development of skilled human resources and technology.

Evidence suggested that majority of the respondents in the survey operated their businesses from rented houses (almost with a percentage of 56.41), while the remaining percentage indicated owners who rented their premises from the government. Thus, this is a challenge for the owners of the enterprises.

With regard to market linkage, $85.63 \%$ of the respondents had no or weak formal and well-organized linkage among themselves and with other institutions. The rest (14.37\%) of the entrepreneurs had developed organized linkage among themselves and with other stakeholders. In addition, the study addressed enterprise linkage with research and training institutions and linkage of enterprises among themselves, i.e., forward and backward linkage with customers. Accordingly, majority of the respondents revealed existence of weak linkage with their customer including forward and backward linkage. Results of open-ended question revealed that most of the enterprises purchase important inputs for their production and operation and sold their products and services for their customers through their own efforts without formal backward and

Table 4 Access to finance

\begin{tabular}{lll}
\hline Access to finance & Frequency & Percentage \\
\hline No & 132 & $64.1 \%$ \\
Yes & 74 & $35.9 \%$ \\
Total & 206 & $100 \%$ \\
\hline
\end{tabular}

Source: Author's computation based on firm survey (2018) 


\section{$\square$ Agriculture $\square$ Trade $\square$ Construction $\square$ Service $\square$ Manufacturing

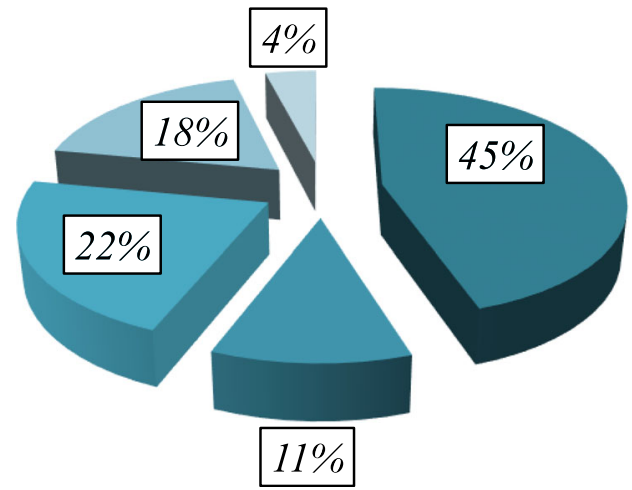

Fig. 2 Sectoral engagement of enterprises. Source: author's computation based on firm survey (2018)

forward linkage market. Thus, for the majority of the enterprises, linkage is their challenge.

Figure 5 reveals that majority of the respondents (47.08\%) were in the age range of 25-35 years followed by those in the age less than 25 years (28.16\%). Indeed, almost $75.24 \%$ of the entrepreneurs are in their prime productive and reproductive ages. This character, thus, could be considered as a prospect of the sector since studies advocate that those younger entrepreneurs have better motivation, energy, and commitment to work and are more inclined to take risks that could bring higher return than aversing the risk of business. The rationale behind this description is that older entrepreneurs are likely to have achieved their initial ambitions in their productive years. The rest 22.33 and $2.43 \%$ were in the age range of 36 to 45 and with age more than 45 years, respectively. The result also indicated that the sector is meeting one of the objectives of the government by creating employment opportunities for the youth since most of the entrepreneurs are young and a productive labor force. And such a productive workforce is, indeed, believed to be an engine for development of the region in particular

\section{Assosa $\square$ Bambasi $\square$ oda $\square$ Menge $\square$ Sherkole $\square$ Homosha $\square$ Kurmuk}

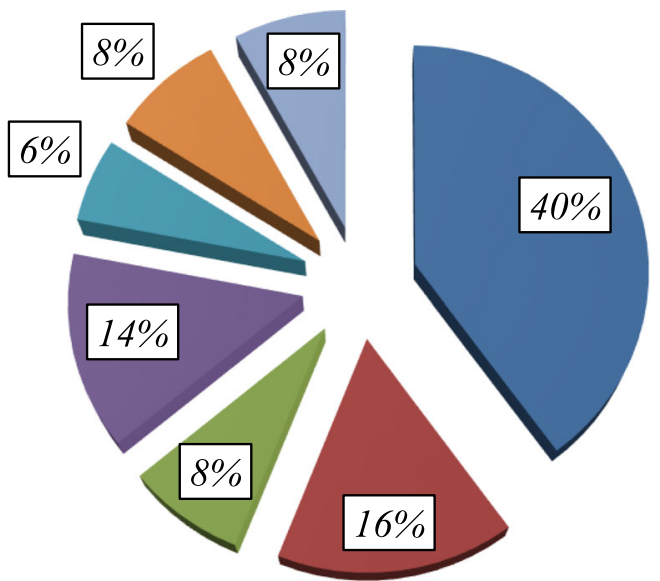

Fig. 3 Operational location of enterprises. Source: author's computation based on firm survey (2018) 


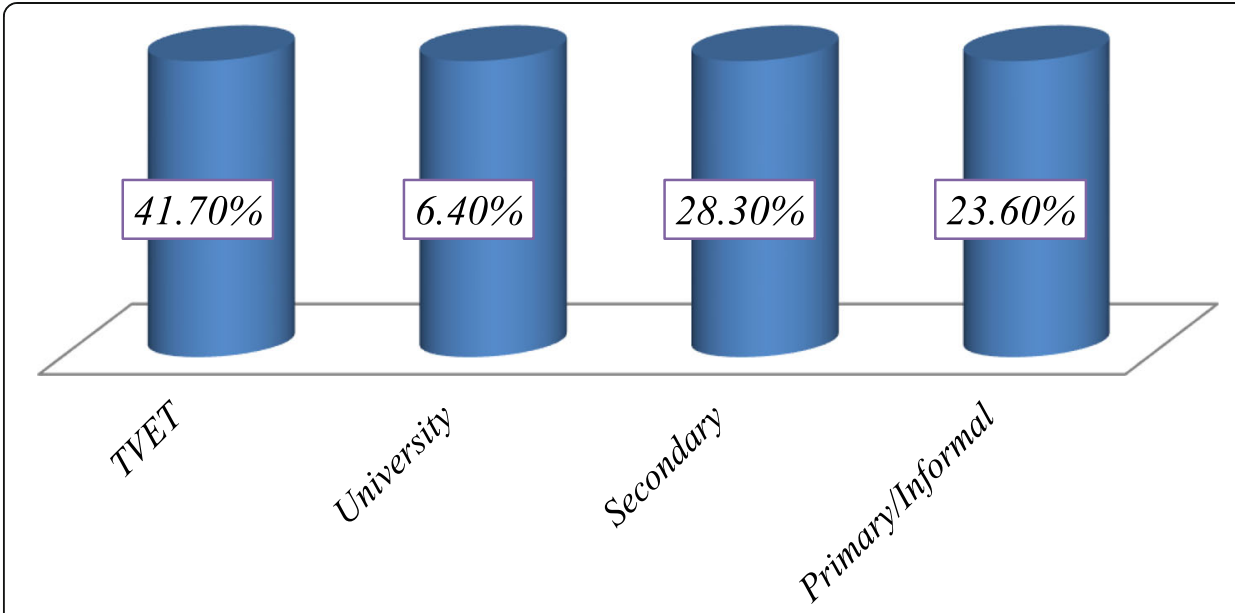

Fig. 4 Educational status of entrepreneurs. Source: author's computation based on firm survey (2018)

and of the country in general though this prospect by itself may not bring the required outcome without the other means.

Figure 6 reveals that majority (55.11\%) of the respondents had operated their businesses for a period of fewer than 3 years followed by $24.76 \%$ with business experience that ranges between 4 and 5 years, while those who had been in operation for more than 5 years shared the least percentage (only 20.13\%) as of the chart depicted in Fig. 6 . Therefore, majority of the enterprises are at their start-up stage experiencing many challenges.

The analysis of descriptive statistics makes a discussion about prospects and challenges of enterprises. Determining the factors that may significantly contribute to enterprises' growth, however, goes beyond the descriptive analysis that requires employment of econometric analysis. Econometrically, therefore, the study used multiple linear regression analysis to identify factors that significantly influence the extent of growth of the enterprises. To this end, capital and employment growth were proposed to be used as means of micro and small scale enterprises' growth measurement.

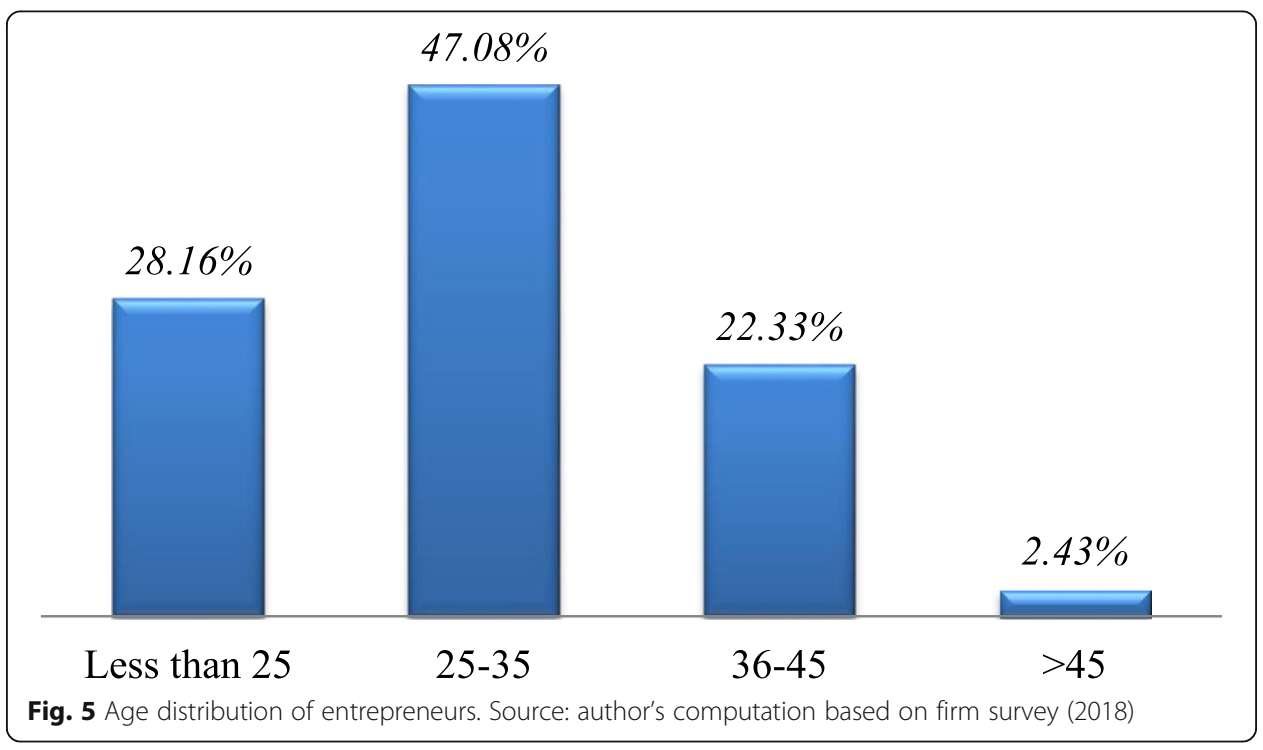


However, there is no variation in employment growth in the enterprises during the study period. In all of the enterprises, there is neither increment nor decrement in the size of employment. Therefore, only capital growth determinants are discussed in the regression analysis.

Diagnostic tests for classical linear regression model assumptions were carried out first before starting discussion on the OLS regression output to explain the influencing factors of enterprise growth. Accordingly, the first assumption required in classical linear regression model that is normality assumption was checked to conduct single or joint hypothesis tests about the model parameters. Indeed, Shapiro-Wilk test was used to test the normality distribution of error term with null hypothesis that residuals are normally distributed. The result of this test shows Prob $>z=0.20039$ which is statistically insignificant, indicating that the residuals are normally distributed supporting the null hypothesis. In addition, multicollinearity test was carried out. The assumption here is explanatory variables are not correlated with one another. The severity of the problem of multicollinearity across the independent variables can be examined in terms of the variance inflation factors (VIF). According to Gujarati (2003), variables are considered as highly collinear if the VIF exceeds 10. In this research, the result of VIF for each explanatory variable included in the regression model is very low (less than 3 ), suggesting that there is no severe multicollinearity problem in the estimated model. Therefore, multicollinearity between the explanatory variables is not considered to be a problem here.

The other assumption of the classical linear regression model is that the regression model used in the analysis is correctly specified. If the model is not correctly specified, the problem of model specification error or model specification bias will be encountered (Gujarati 2003). Thus, model specification with regard to omission of variables can be formally tested using Ramsey's RESET test, which is a general test for misspecification of functional form (Brooks 2014). Accordingly, Ramsey RESET test was performed for model specification with null hypothesis that the model has no omitted variables and its result was statistically insignificant supporting the null hypothesis

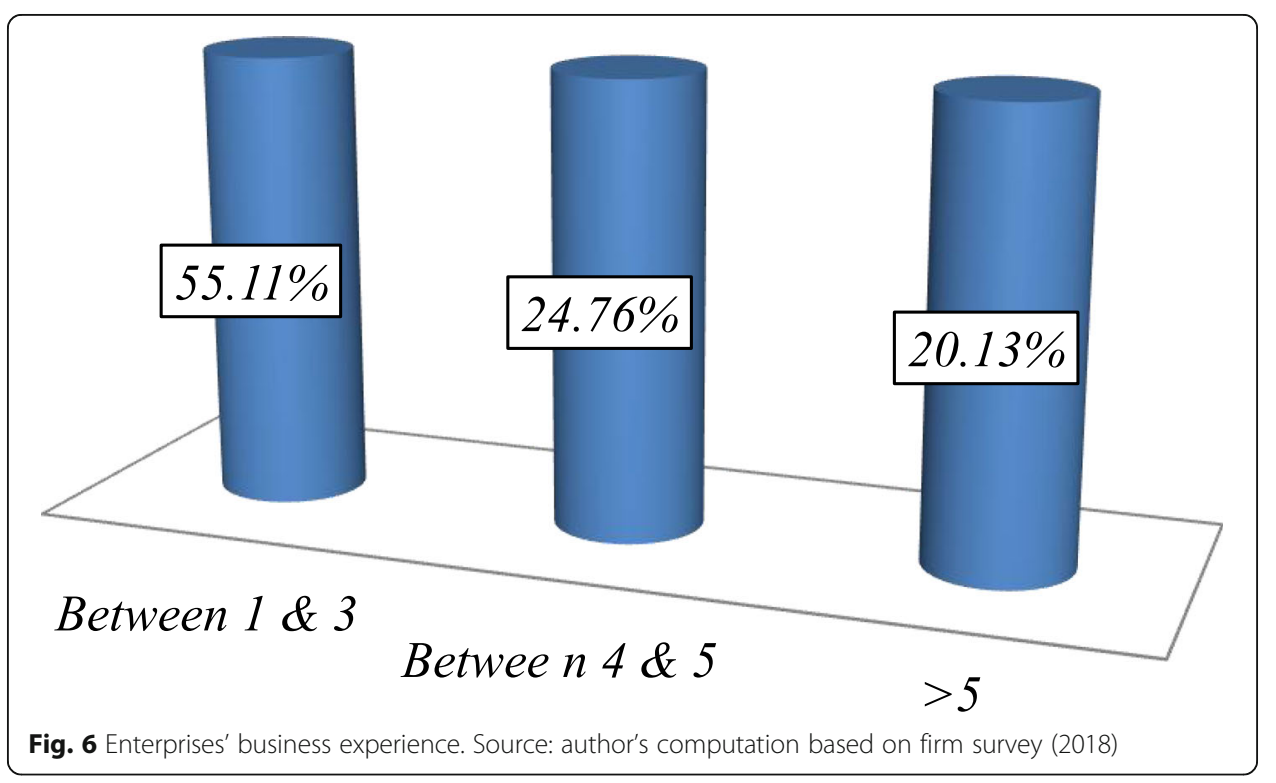


(Prob $>F=0.2528$ ). In addition, Breusch-Pagan/Cook-Weisberg test for heteroscedasticity was used with null hypothesis that variance of error is constant. To this end, the result of the test was statistically significant, indicating existence heteroscedasticity (Prob $>X^{2}=0.0005$ ). Assuming homoscedastic disturbances when heteroscedasticity is present, however, can lead to biased statistical results. Therefore, to ensure validity of the statistical results, problem of heteroscedasticity was controlled using robust standard error.

Evidence of the regression output, depicted in Table 5, revealed that enterprises which started their business operation with higher initial investment grow faster than their counterparts which started their business operation with relatively smaller initial investment, as far as money is created from money and lower money creates lower and higher investment brings better return. However, financial resources to entrepreneurs at their establishment or initial stage are the major obstacles in doing business as discussed in the descriptive statistics. In line with this, the current study is consistent with the research findings of Ahiawodzi 2012; Tefera et al. 2013, and Fissiha 2016. On the other side, the finding of this study contradicts with that of Gebreeyesus (2007) that indicated negative impact of initial capital on growth suggesting fast growth of enterprises with lower initial capital than those with higher capital.

The study confirmed that enterprises with better access to land as working premise grow faster than their counterparts. However, many of the micro and small scale enterprises in the region suffer from lack of appropriate land for operation although this factor is among the main determinants of upgrading for most enterprises. This means that micro and small scale enterprises' owners who want to upgrade are particularly hindered by access to land as a working premise though the enterprises' owners decide the expansion of their business. The finding of this study is consistent with that of Loewe et al. (2013).

The evidence of the study revealed insignificant effect of gender on growth of enterprises though there is an argument that favors growth of man-owned enterprises than woman-owned for the fact that women have dual, i.e., domestic and productive, responsibility than men. Therefore, the evidence of the study did not provide confirmation that female entrepreneurs face more difficulties than male entrepreneurs in upgrading their enterprises in the region.

The Stata output revealed that access to finance influenced positively and significantly the capital growth at $5 \%$ significant level. This implies that enterprises with access to finance grow better than credit-constrained enterprises. However, majority of the enterprises face various challenges in securing debt finance. Poor lending procedure and lack of collateral were found as principal reasons for not acquiring finance according to evidence of entrepreneurs from open-ended questions. This may be due to the fact that the formal financial institutions are in fear of micro and small scale enterprises for several reasons including lack of track record of financial transactions, irregular record keeping, and high cost involved in serving unorganized enterprises. Evidence of the current study is, therfore, consitent with the research finding of empirical study made by Abay et al. (2014) with the title of "External factors affecting the growth of micro and small enterprises in Ethiopia" with a special focus on enterprises operated in Shire Indasselassie Town of Tigray Regional State. This evidence is also consistent with a study made by Leza et al. (2016) on determinants of employment growth of micro and 
Table 5 Regression output of enterprises' growth determinants

\begin{tabular}{|c|c|c|c|c|}
\hline Capital growth & Coef. & Robust std. err. & $t$ & $P>|t|$ \\
\hline Initial capital & 0.1525304 & 0.0469502 & 3.25 & 0.001 \\
\hline Land & 11704.75 & 6150.119 & 1.90 & 0.058 \\
\hline Access to finance & 14379.44 & 4139.49 & 3.47 & 0.001 \\
\hline Age & -2445.354 & 1365.645 & -1.79 & 0.075 \\
\hline Gender & 190.0727 & 2867.169 & 0.07 & 0.947 \\
\hline \multicolumn{5}{|c|}{ Location reference (Assosa) } \\
\hline Sherkole & -6779.319 & 3334.599 & -2.03 & 0.043 \\
\hline Oda & -15840.52 & 6417.432 & -2.47 & 0.014 \\
\hline Kurmuk & -1986.541 & 5711.893 & 0.35 & 0.728 \\
\hline Menge & 57770.31 & 26765.91 & 2.16 & 0.032 \\
\hline Homosha & -1162.441 & 3950.246 & -0.29 & 0.769 \\
\hline Bambasi & -5598.967 & 3811.54 & -1.47 & 0.143 \\
\hline \multicolumn{5}{|c|}{ Sector reference (manufacturing) } \\
\hline Agriculture & 6525.055 & 8148.432 & 0.80 & 0.424 \\
\hline Trade & 15810.12 & 9203.484 & 1.72 & 0.087 \\
\hline Service & 10041.97 & 8528.645 & 1.18 & 0.240 \\
\hline Construction & 39743.9 & 15533.48 & 2.56 & 0.011 \\
\hline Motivation & 3840.297 & 6054.97 & 0.63 & 0.527 \\
\hline \multicolumn{5}{|c|}{ Education reference (TVET) } \\
\hline Informal/elementary & 6375.578 & 9502.035 & 0.67 & 0.503 \\
\hline Secondary & 9446.27 & 12964.7 & 0.73 & 0.467 \\
\hline University & 7371.459 & 11206.2 & 0.66 & 0.511 \\
\hline Link & 25432.32 & 9362.707 & 2.72 & 0.007 \\
\hline Own & 6231.477 & 5313.219 & 1.17 & 0.242 \\
\hline$I C T$ & 1513.364 & 7293.996 & 0.21 & 0.836 \\
\hline Record & 6340.358 & 4279.227 & 1.48 & 0.140 \\
\hline FM practice & 919.3751 & 11053.14 & 0.08 & 0.934 \\
\hline Cons & -10500.99 & 8956.045 & -1.17 & 0.242 \\
\hline
\end{tabular}

Number of observations $=206$

$F(26,179)=7.86$

Prob $>F=0.0000$

$R^{2}=0.5332$

Root MSE = 32837

small enterprises in the Wolaita Zone, southern nations, nationalities, and people's region of Ethiopa.

The capital growth of enterprises was negatively affected by their age at less than $1 \%$ significant level though positive association was expected between business experience and growth of enterprises. This reveals that value growth of newly established micro and small scale enterprises is better than early established firms. This may be due to the argument that older firms might have problems in adapting their strategies to changing market conditions, whereas new firms may not in order to have higher growth. The evidence of the study is consistent with that of Gebreeyesus (2007) and with the research carried out by Leza et al. (2016) on the determinants of employment growth of micro and small enterprises in Wolaita Zone, Ethiopia. 
Location of enterprises was also included in the econometric model to see whether or not it is correlated with the capital growth of micro and small scale enterprises. More specifically, whether or not the capital growth of enterprises located in Assosa Wereda differs from those operating in other weredas. The regression result revealed that micro and small scale enterprises located in Menge Wereda grow faster than the enterprises in Assosa Wereda. On the other side, however, the enterprises located in Oda Wereda and Sherkole Wereda grow slower compared with the enterprises in Assosa Wereda. This finding could be related to the availability of different services, infrastructures, and inadequate market linkage, as long as the presence or absence of which can affect the enterprise's capital growth.

Enterprises' sector was also included in the model to see whether or not it is correlated with the capital growth of micro and small scale enterprises with special reference to the manufacturing sector. It was expected that micro and small scale enterprises engaged in manufacturing sector tend to grow faster than other sectors in the Ethiopian context. This hypothesis was developed by considering the vision of industrial development plan that focused on building an industrial sector with the highest manufacturing capability in Africa which is diversified, globally competitive, environmentally friendly, and capable of significantly improving the living standards of the Ethiopian people by the year 2025 by providing special support for the sector. In line with this, a particular emphasis is given to the promotion of micro and small scale enterprises by means of providing special support to those enterprises that engaged in the manufacturing sector followed by the construction sector in order to achieve the objectives of micro and small enterprise development policy and strategy and in line with the growth and transformation plan. However, an empirical result of this study failed to support this expectation; rather, trade and construction sectors grow faster than the manufacturing sector not as expected.

In addition to the above discussion, evidence of the regression output indicates absence of significant effect of entrepreneur's motivation, adoption of technological services, and proper recording of financial transactions and financial management practice on growth of enterprise though the study conceptualized their influence based on literature. As of the regression output, linkage of micro and small scale enterprises affects capital growth positively. The implication here is that enterprises with higher linkage with different organizations at trade exhibition and bazaar by presenting their goods and services and then exchanging their addresses with potential and actual customers grow faster than their counterparts. With regard to market, these business firms can have forward linkage with customers or other resellers and backward linkage with their raw material suppliers to get the needed quality and quantity of the materials which in turn helps to produce quality goods or services that could satisfy the customer's needs and wants which in turn improves their growth potential in capital. The rationale behind is that if customers are satisfied, they buy frequently the enterprise's product and promote it which could increase the enterprise's product sales and its capital growth. On the contrary, as discussed in the descriptive statistics, most micro and small scale enterprises under study have weak linkage with market as well as with government sectors though the variable has positive influence on capital growth.

To capture ownership effect on the growth of micro and small scale enterprises, ownership structure of firms was included in the study to investigate whether or not an 
enterprise ownership by private or by associations has influence on growth. The finding seems to suggest no evidence on the nexus between ownership structure of enterprises and capital growth.

Owners' education was supposed to determine the enterprises' capital growth with special reference to TVET in that TVET graduate entrepreneurs grow faster. Education being the basic human endowment could enhance the promoters' access to new information and their ability to process such information resulting in efficient production and distribution of goods and services. However, the regression output of the empirical evidence in the current study failed to show significant effect of education on capital growth.

\section{Conclusion and recommendation}

This paper provides new empirical evidence on micro and small scale enterprises' growth influencing factors based on the data acquired from 206 entrepreneurs in Benishangul-Gumuz Regional State of Ethiopia using regression analysis. The result of regression output revealed statistically significant evidence of seven explanatory variables out of 14 variables in determining micro and small scale enterprises' growth at $10 \%$ of significance level. To this end, initial capital, access to land, access to finance, firm location, sectoral engagement, market linkage, and business experience were significant in one hand. On the other side, however, gender, education, ownership structure, record keeping, financial management practice, and information and communication adoption are found to be insignificant variables.

Evidently, the regression output revealed that enterprises which started their business operation with higher initial investment grow faster than their counterparts which started their business operation with relatively smaller initial investment. In addition, enterprises with better access to land as working premise grow faster than their counterparts. In the same vein, the evidence revealed that enterprises with access to finance grow better than credit-constrained enterprises though majority of the enterprises face various challenges in securing debt finance from formal institutions. However, the finding revealed that the growth of newly established micro and small scale enterprises is better than that of early established firms. The regression result also revealed that enterprises located in Menge Wereda grow faster than enterprises in Assosa Wereda. On the other side, however, enterprises located in Oda Wereda and Sherkole Wereda grow slower compared with enterprises in Assosa Wereda. With regard to market linkage, enterprises with higher linkage with different organizations through trade exhibition and bazaar grow faster than their counterparts.

The findings of this study, therefore, suggest that enterprises with lower capital growth should take actions for better improvement of their growth and their contribution for the regional as well as national economy by means of creating strong linkage with customers, preparing a formal recording of economic transactions, and improving financial management practice for easy access to finance. In addition, the findings of the paper suggest entrepreneurs to organize exhibitions and bazaars in urban centers at regional, zonal, and wereda levels to have better market share which is important for capital growth. With regard to finance, micro and small enterprises' policy and strategy suggests micro finance institutions to be the sole providers of saving and credit services to the sector. However, micro finance institutions by themselves are in limited finance 
in general. The worst limitation is in micro finance institutions in Benishangul-Gumuz. Therefore, the policy should reconsider financing strategy of the sector as long as finance is a life blood for business operation. Moreover, along with literature contribution, the present study contributes to the ongoing debate in MSSEs' literature through its investigation on determinants of growth in emerging region.

It should be noted, however, that this paper used cross-sectional data of 206 firms and the findings may not be able to make generalization to other firms over a period of time. Therefore, it is believed that future panel surveys and availability of other data may necessitate corresponding revisions of growth determinant factors in order to have a comprehensive solution for the growth-constraining factors of small business.

\section{Abbreviations}

MSSEs: Micro and small scale enterprises; ICT: Information and communication technology; NBE: National Bank of Ethiopia; MFIs: Micro Finance Institutions; TVET: Technical and vocational education and training

\section{Acknowledgements}

Not applicable

\section{Author's contributions}

The author, Hayelom Abrha, personally undertook this research paper. The author also read and approved the final manuscript.

\section{Author's information}

Not applicable

Funding

This research is sponsored by the Assosa University.

\section{Availability of data and materials}

The data that support the findings of the study can be obtained from the author based on request.

Ethics approval and consent to participate

Not applicable

Consent for publication

The author personally approve that the paper should be published in your journal.

Competing interests

The author declare that there is no competing interest

Received: 28 October 2019 Accepted: 15 April 2020

Published online: 29 June 2020

\section{References}

Abara, G., \& Banti, T. (2017). Role of financial institutions in the growth of micro and small enterprises in Assosa Zone. Research Journal of Finance and Accounting, 8(3), 36-40.

Abay, H. H., Tessema, F. G., \& Gebreegziabher, A. H. (2014). External factors affecting the growth of micro and small enterprises (MSEs) in Ethiopia: A Case Study in Shire Indasselassie Town, Tigray. European Journal of Business and Management, 6(34), 134-145.

Abdul-Rahamon, O. A., \& Adejare, A. T. (2014). The analysis of the impact of accounting records keeping on the performance of the small scale enterprises. International Journal of Academic Research in Business and Social Sciences, 4(1), 1-17.

Abebe, A., Robe, M., \& Maru, M. (2016). Assessment on challenges and performances of micro and small enterprises in Benishangul Gumuz Regional State: formalization is the way forward. Research for Community and Self not for Shelf. Assosa University, Ethiopia.

Adem, M., Worku, H., \& Beyene, D. (2014). Constraints and growth potentials of micro and small enterprises: case from Mekelle City. International Journal of Scientific and Research Publications, 4(12), 1-7.

Afande, F. O. (2015). Factors influencing growth of small and microenterprises in Nairobi Central Business District. Journal of Poverty, Investment and Development, 9, 105-137.

Ahiawodzi, A. K. (2012). Access to credit and growth of small and medium scale enterprises in the Ho municipality of Ghana. British Journal of Economics, Finance and Management Sciences, 6(2), 34-51.

Ahmad, M., Ahmad, E., Kahut, M. B., \& Murtaza, G. (2012). New determination of factors affecting the growth of small and medium sized enterprises in Pakistan. Interdisciplinary Journal Of Contemporary Research In Business, 4(6), 513-530.

Alemayehu, D., \& Gecho, Y. (2016). Determinants of micro and small enterprises growth: the case of Durame Town, Kembata Tembaro Zone, Southern Nations and Nationalities and Peoples Region, Ethiopia, 2016. International Journal of Business and Economics Research, 5(5), 161-175. 
Amentie, Negash, \& Kumera. (2016). Barriers to growth of medium and small enterprises in developing country: case study Ethiopia. Journal of Entrepreneurship \& Organization Management.

Anga, R. M. (2014). Determinants of small and medium scale enterprises in Nigeria. JORIND, 12(1).

Assefa, B., Zerfu, A., \& Tekle, B. (2014). Identifying key success factors and constraints in Ethiopia's Mse development: an exploratory research. Ethiopian Development Research Institute.

Attom, B. E. (2013). Cash management practices by micro and small-scale enterprises at Kasoa in the central region of Ghana. Asian Journal of Business and Management Sciences, 3(2), 1-12.

Aynadis, Z., \& Mohammednur, M. (2014). Determinants of growth of micro and small enterprises in Ethiopia (a case of MSEs in Mekelle City, Tigray). International Journal of Advance Research in Computer Science and Management Studies, 2(6), 149-157.

Bhattacherjee, A. (2012). Social science research: principles, methods, and practices (2nd ed.) USA.

Brooks, C. (2014). Introductory Econometrics for Finance (3rd ed.). New York: Cambridge University Press.

Creswell, J. W. (2012). Educational research: planning, conducting, and evaluating quantitative and qualitative research (4th ed.) s.l.:Pearson Education, Inc. Boston.

Debelo, B. K., Teshome, A., \& Minalu, T. (2015). Factors affecting developments of micro and small enterprises. International Journal of Scientific and Research Publications, 5(1), 1-10.

Emmanuel, A. T., Dele, A. O., \& Odunlami, I. B. (2013). Determinants of small and medium enterprises (SMEs) performance in Ekiti State, Nigeria: a business survey approach. European Journal of Humanities and Social Sciences, 27(1).

Esubalew, A. A., \& Raghurama, A. (2017). Micro, small and medium enterprises (MSMEs) development strategies in Ethiopia: retrospective and prospective analysis. International Journal of Commerce, Business and Management, 6(1), 11-20.

Feleke, D. (2015). Factors affect the growth of micro and small enterprises in Hossana Town, SNNPR. Jimma: Jimma University.

Fissiha, Y. (2016). Determinants of the growth of MSEs in Ethiopia: the case study of Bahir Dar City Administration. The International Journal Of Business \& Management, (7), 75-96.

Gawali, R. B., \& Gadekar, A. (2017). Financial management practices in micro, small and medium enterprises-an exploratory analysis with the help of literature review. International Journal of Research in Finance and Marketing, 7(6), 45-59.

Gebreeyesus, M. (2007). Growth of micro-enterprises: empirical evidence from Ethiopia. Ethiopian Development Research Institute (EDRI).

Gebru, G. H. (2010). Research methods and analysis for business studies: a holistic approach. Mekelle: College of Business and Economics, Mekelle University.

Gujarati, D. N. (2003). Basic econometrics (4th ed.) s.l.:McGraw-Hill. New York.

Jennifer, K., \& Dennis, O. (2015). Financial management practices on growth of small and medium enterprises: a case of manufacturing enterprises in Nairobi County, Kenya. IOSR Journal of Business and Management, 17(8), 65-77.

Kahando, D. M., Maina, T. M., \& Maina, C. M. (2017). An appraisal of financial management practices on the growth of micro enterprise in Kenya. Journal of Business and Economic Development, 2(1), 63-70.

Kothari, C. R. (2004). Research methodology (2nd ed.). New Delhi: Newage International Limited publishers.

Lakew, D. M., \& Birbirsa, Z. A. (2017). Accounting and reporting practice of micro and small enterprises in West Oromia Region. Research Journal of Finance and Accounting, 8(9).

Leza, T., Rajan, S., \& Kuma, B. (2016). Determinants of employment growth of micro and small enterprises in Wolaita Zone, Ethiopia. International Journal of Current Research, 8(12), 43177-43186.

Loewe, M., Al-Ayouty, I., Altpeter, A., Borbein, L., Chantelauze, M., Kern, M., et al. (2013). Which factors determine the upgrading of small and medium-sized enterprises (SMEs)? The case of Egypt. German Development Institute in cooperation with the Egyptian Center for Economic Studies (ECES).

Mbugua, J. K., Mbugua, S. N., Wangoi, M., Ogada, J. O., \& Kariuki, J. N. (2013). Factors affecting the growth of micro and small enterprises: a case of tailoring and dressmaking enterprises in Eldoret. International Journal of Business and Social Science, 4(15), 285-293.

Mutua, O. M. (2015). Effect of bookkeeping on the growth of small and medium enterprises in Chuka Town. European Journal of Business and Social Sciences, 4(7), 102-112.

Nathan, O. F., Molefhe, L., Mupimpila, C., Nkuba, M., \& Okurut, M. L. (2015). Determinants of sme growth in Botswana. IDR, 13(1), 51-70.

Nganda, J. W., Wanyonyi, K. W., \& Kitili, E. M. (2014). Determinants of growth of small and medium enterprises in Kakamega central sub-county, Kenya. Journal of Business Administration and Management Sciences Research, 3(3), 022-031.

Ntim, A. L., Evans, O., \& Anthony, F. (2014). Accounting practices and control systems of small and medium size entities: a case study of Techiman municipality. Journal of Finance and Accounting, 2, 30-40.

Nyang'au, S. P. (2014). The influence of entrepreneurship on the growth of micro and small enterprises in Thika Town, Kenya. International Journal of Business, Humanities and Technology, 4(2), 82-87.

Oppong, M., Owiredu, A., \& Churchill, R. Q. (2014). Micro and small scale enterprises development in Ghana. European Journal of Accounting Auditing and Finance Research, 2(6), 84-97.

Papadaki, E., \& Chami, B. (2002). Growth determinants of micro-businesses in Canada. In Small business policy branch industry Canada (pp. 1-55).

Seyoum, A., Aragie, M., \& Tadesse, D. (2016). Growth of micro and small enterprises in Addis Ababa City Administration: a study on selected micro and small enterprise in Bole Sub City. International Journal of Scientific and Research Publications, $6(1), 581-592$

Tarfasa, S., Ferede, T., Kebede, S., \& Behailu, D. (2016). Determinants of growth of micro and small enterprises: empirical evidence from Ethiopia.

Tefera, H., Gebremichael, A., \& Abera, N. (2013). Growth determinants of micro and small enterprises: evidence from Northern Ethiopia. Journal of Economics and Sustainable Development, 4(9), 127-134.

Victoria, M., Samuel, B., Lloyd, C., \& Lazarus, M. (2011). Determinants of small and medium enterprises failure in Zimbabwe: a case study of Bindura. 2(5), 82-89.

Wolde, F., \& Geta, E. (2015). Determinants of growth and diversification of micro and small enterprises: the case of Dire Dawa, Ethiopia. Developing Country Studies, 5(1), 61-75.

Woldeyohanes, H. T. (2014). Dimensions and determinants of growth in micro and small enterprises: empirical evidence from Mekelle City, Ethiopia. Agris on-line Papers in Economics and Informatics, 6(3), 104-115. 
Yamane, T. (1967). Statistics: An introductry analysis (2nd ed.). New York: Harper and Row.

Yeboah, M. A. (2015). Determinants of SME growth:an empirical perspective of SMEs in the Cape Coast Metropolis, Ghana. Journal of Business in Developing Nations, 14, 1-31.

Zhou, H., \& de Wit, G. (2009). Determinants and dimensions of firm growth. SCALES EIM Research Reports (H200903) https:// doi.org/10.2139/ssrn.1443897.

\section{Publisher's Note}

Springer Nature remains neutral with regard to jurisdictional claims in published maps and institutional affiliations.

Submit your manuscript to a SpringerOpen ${ }^{\odot}$ journal and benefit from:

- Convenient online submission

- Rigorous peer review

- Open access: articles freely available online

- High visibility within the field

- Retaining the copyright to your article

Submit your next manuscript at $\boldsymbol{\nabla}$ springeropen.com 